\title{
Automated Assay of Glycosidases ${ }^{1}$
}

\begin{abstract}
The Technicon Basic AutoAnalyzer sampler system was modified for simultaneous sampling of glycosidase(s) and substrate-buffer solutions. The inexpensive modification allows performance of automated enzyme analyses and enzyme kinetic studies with minimal consumption of substrate and/or enzyme.
\end{abstract}

Automated methodology for monitoring the presence of one or more glycosidases in biological extracts has been described (1-7). These procedures require use of large amounts of synthetic glycoside(s) $(1-4,6,7)$, compound automated systems (5), or extensive mechanical and/or electrical alterations of existing apparatus (8). The present paper describes a simple modification of the Technicon Basic AutoAnalyzer sampler system which allows simultaneous sampling of enzyme and substrate-buffer solutions and requires small amounts of substrate and enzyme for automated enzyme assay. The versatility of this system for the assay of glycosidases and the study of their kinetic parameters is demonstrated utilizing bovine testicular $N$-acetyl- $\beta$-hexosaminidase (EC 3.2.1.30).

\section{MATERIALS}

$\beta$-Hexosaminidase. Bovine testicular $\beta$-hexosaminidase, purified 270 fold was prepared by the method of Sarber and Jourdian (9). One unit of activity is defined as that amount of enzyme that releases $1 \mu \mathrm{mol}$ of $p$ nitrophenol from $p$-nitrophenyl 2-acetamido-2-deoxy- $\beta$-D-glucopyranoside (pNP-GlcNAc) ${ }^{2}$ at $37^{\circ} \mathrm{C}$ in $1 \mathrm{~min}$.

Substrate and buffers. For routine enzyme assay, the substrate solution was prepared in the following manner: pNP-GlcNAc $(136.8 \mathrm{mg})$ dissolved in $1 \mathrm{ml}$ of dimethyl formamide was added to $19 \mathrm{ml}$ of McIlvaine buffer, $\mathrm{pH} 4.5(10)$, containing $0.5 \%(\mathrm{w} / \mathrm{v}) \mathrm{BSA}$.

Wash and "stopping" solutions. The wash solution contained $0.1 \%$ $(\mathrm{w} / \mathrm{v}) \mathrm{BSA}$ in $0.03 \%(\mathrm{v} / \mathrm{v})$ Triton $\mathrm{X}-100$. The stopping solution was $1.93 \mathrm{M}$ $\mathrm{NH}_{4} \mathrm{OH}$ adjusted to $\mathrm{pH} 11.5$ with hydrochloric acid.

$p$-Nitrophenyl 2-acetamido-2-deoxy- $\beta$-D-glucopyranoside, Triton X100 , and crystalline bovine serum albumin were obtained from the Sigma Chemical Company, St. Louis, Missouri.

\footnotetext{
${ }^{1}$ This work supported in part by Grant AM 1053 from the National Institute of Arthritis, Metabolic and Digestive Diseases, National Institutes of Health, and by a grant from the Arthritis Foundation, Michigan Chapter.

${ }^{2}$ Abbreviations used: pNP-GlcNAc, $p$-nitrophenyl 2-acetamido-2-deoxy- $\beta$-D-glucopyranoside; BSA. bovine serum albumin.
} 


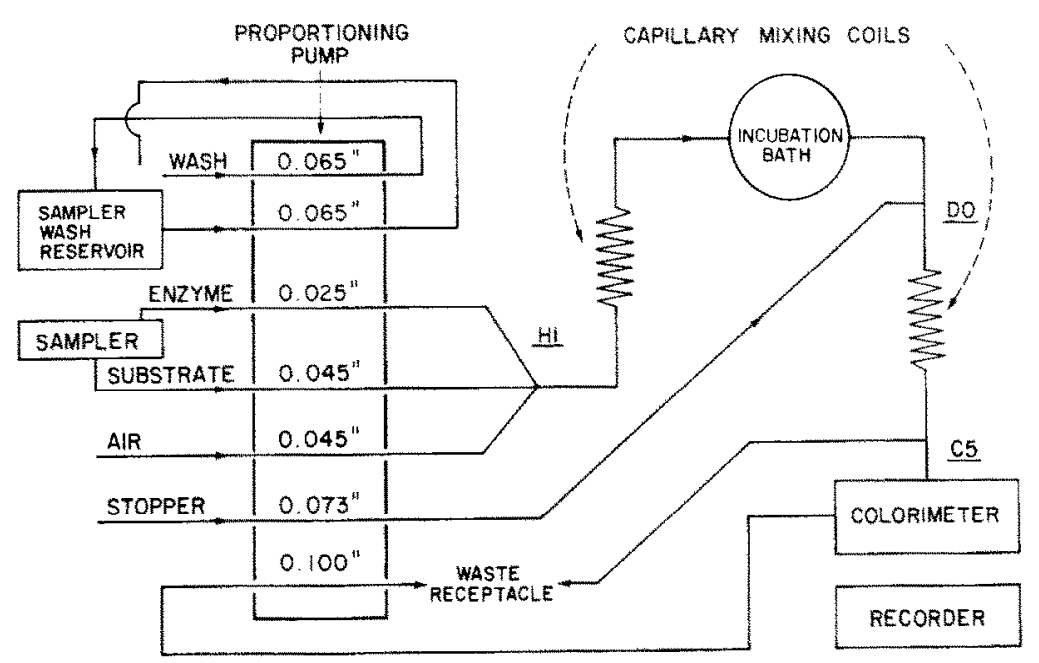

Frc. 1. Technicon AutoAnalyzer manifold for automated assay of $\beta$ - $N$-acetylhexosaminidase as modified from Beck and Tappel (8). Stopper = stopping solution.

\section{APPARATUS}

Flow system. The manifold for automated assay of the glycosidases was a modification of that described by Beck and Tappel (8) (Fig. 1). The drain port for the sampler wash reservoir was closed and the wash solution was rerouted as indicated in the figure. The two capillary mixing coils were placed in the system immediately after the joining of substrate and enzyme streams $(\mathrm{HI})$ and the addition of stopping solution (DO), respectively. The heating coil had an inside diameter of $2 \mathrm{~mm}$ and was $337 \mathrm{~cm}$ in length from the inlet to the exit port. The $p$-nitrophenol released during the incubation period at $37^{\circ} \mathrm{C}$ was passed through a Techicon colorimeter (Model 1) equipped with an $\mathrm{N}$-tubular flow cell with a $1.5-\mathrm{cm}$ light path and a 420 -nm light filter. Absorbance was read as optical density on a single pen Technicon recorder. The sample cam used (sample to wash ratio, 1:2) allowed assay of 50 samples per hour.

Modification of the sampler plate, probe support, and was reservoir. The sampler plate was modified to contain a second inner row of sample cups in the manner shown in Fig. $2 \mathrm{~A}$. Holes $(1.3 \mathrm{~cm}$ in diameter) were drilled in the sampler plate $1.5 \mathrm{~cm}$ from the center of each original sample cup hole. To accomodate the lip of the sample cups in the sampler plate each cup hole was enlarged to a depth of $1 \mathrm{~mm}$ using a milling cutter of $1.5 \mathrm{~cm}$ in diameter.

The sample probe support was constructed from a Lucite block $(3 \times 1.3$ $\times 1.3 \mathrm{~cm}$ ) as shown in Fig. 2B. Two sample probe holes, each $1.2 \mathrm{~mm}$ in diameter, were drilled $1.5 \mathrm{~cm}$ apart. The sample probes were secured with Teflon round head screws $(8 / 32 \times 1 / 2$ in. $)$, allowing adjustment to an 

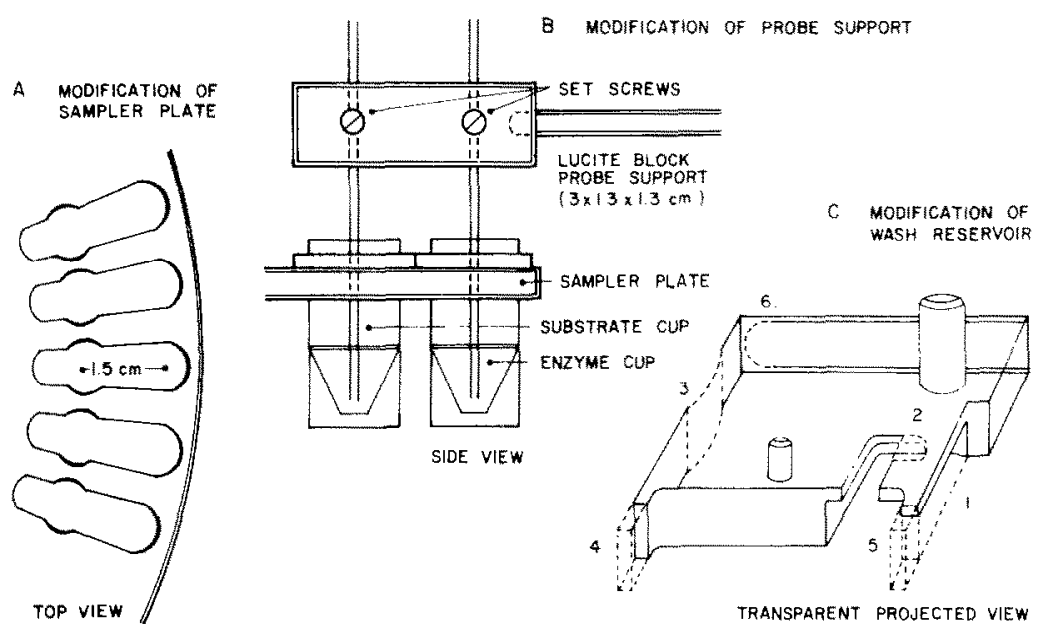

FiG. 2. Equipment modification: (A) modification of Technicon AutoAnalyzer sampler plate; (B) modified Technicon AutoAnalyzer probe support: and (C) modification of the Technicon AutoAnalyzer sampler wash reservoir.

appropriate depth in the sample cup. A hole $(7 \mathrm{~mm}$ in depth and $4 \mathrm{~mm}$ in diameter) was drilled into one end of the Lucite support block and a stainless-steel support arm $(4 \times 70 \mathrm{~cm})$ was inserted. The support arm was affixed to the sample probe clamp in the same manner as that for the single probe support.

The addition of a second sample probe required structural modification of the wash reservoir so that the path of the sample probe tips was not impeded during cycling between the wash reservoir and the sample cups (Fig. 2C). The support [1] in the rear of the reservoir was removed. The positioning slot [2] was altered as indicated to allow movement of the reservoir toward the sample plate $(5 \mathrm{~mm})$. A groove [3] (1-mm deep and $13-\mathrm{mm}$ wide) was milled in the front face of the reservoir $12 \mathrm{~mm}$ from the top edge. The height of the reservoir was reduced by shortening the legs [4 and 5] to $2 \mathrm{~mm}$ in length, and a $2-\times 7-\mathrm{mm}$ section of the inside top front portion of the reservoir [6] was milled out to a depth of $7 \mathrm{~mm}$.

\section{METHODS}

Assay of enzyme activity. Appropriate amounts of bovine testicular hexosaminidase (normal reaction mixtures contained $3.6 \times 10^{-3}$ units in $0.1 \mathrm{ml}$ ) were placed in each of the sample cups in the outer row. The substrate-buffer mixture of appropriate concentration and $\mathrm{pH}$ (routinely, $0.02 \mathrm{M}$ substrate, buffered at $\mathrm{pH} 4.5$ ) was placed in the sample cups in the inner row. For kinetic studies the substrate-buffer solutions were used as prepared or diluted with buffer to an appropriate pNP-GlcNAc concen- 


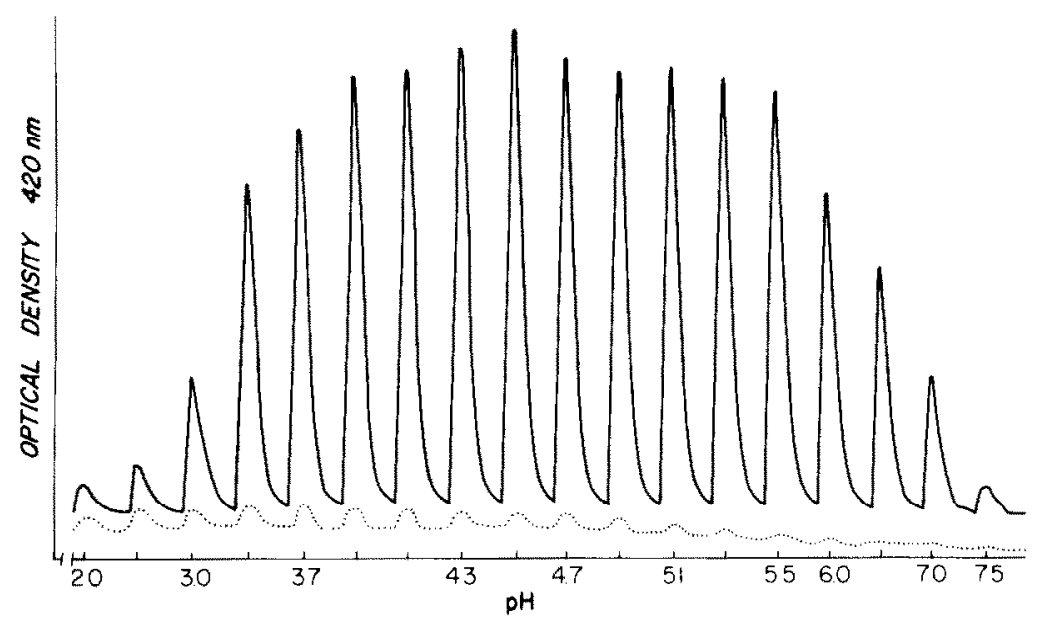

Fic. 3. The effect of $\mathrm{pH}$ on the hydrolysis of pNP-GIcNAc by bovine testicular $N$-acetylhexosaminidase. The assay conditions were those described in the text under Assay of Enzyme Activity. One-tenth milliliter of enzyme containing $59 \mathrm{ng}$ of enzyme protein (3.6 $\times 10^{-3}$ units) in $0.5 \%$ BSA was added to alternate cups in the outer row of the sampler tray. $p$-Nitrophenol released from pNP-GIcNAc during incubation with enzyme at each $\mathrm{pH}$ value is shown by the solid line $(\longrightarrow)$; the substrate blank. by the dotted line $(., \cdots)$.

tration. Routinely, $0.2 \mathrm{ml}$ of substrate was added to $0.5-\mathrm{ml}$ conical bottom sample cups.

Study of enzyme rate. For enzyme rate studies a modification of the procedure of Morganstern et al. (11) was employed; the modified manifold described above was used in conjunction with a two-speed Technicon Proportioning Pump II. The flow system was designed such that seven samples could be entrained in the system at the normal pump speed. The fast wash cycle was activated immediately after the seventh sample passed through the $\mathrm{Hl}$ fitting. Entrance of the last sample into the system was ascertained by observing passage of the air bubble caused by exposure of the tips of the sample probes to air during movement of the sample probe support between the wash reservoir and sampler cups.

\section{RESULTS AND DISCUSSION}

Under the experimental conditions described product formation was linear with enzyme concentration between $5.2 \times 10^{-5}$ and $3.6 \times 10^{-3}$ units of added enzyme and linear with respect to time for at least $440 \mathrm{~s}$. In studies involving determination of $\mathrm{pH}$ optima, effects of inhibitors, etc., alternate sets of sample cups contained distilled water (Fig. 3). This procedure promoted quantitative flushing of chromagen from the $15-\mathrm{mm} \mathrm{N}$-tubular flowthrough cell and establishment of a constant baseline value. Using $p$-nitrophenol as a reference standard a linear pen response was obtained between the concentrations of 0.038 and $1.3 \mathrm{nmol}$. In these studies, the 


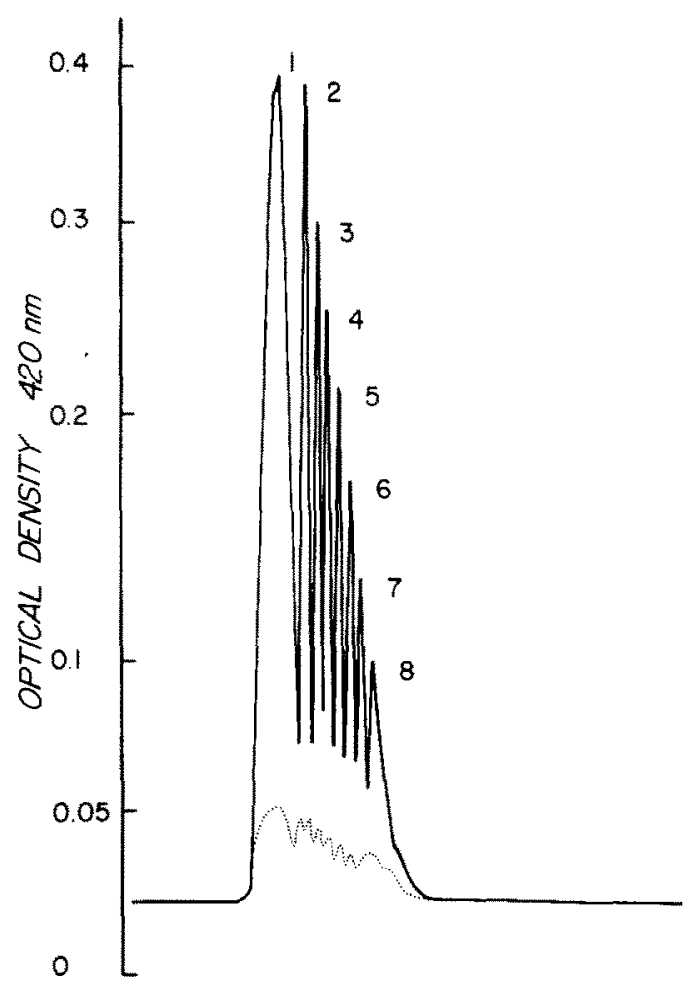

FIG. 4. Use of the modified Technicon system for the determination of the initial reaction rate of bovine testicular $N$-acetylhexosaminidase by the fast flow technique of Morgenstern et al. (11). The assay conditions were those described under Methods. An initial reaction mixture [1] was entrained at the normal pump speed and served as a control to insure the validity of the optical density reading obtained for a duplicate reaction mixture entrained and measured at the fast flow rate [2]. p-Nitrophenol released from pNP-GlcNAc during incubation with $N$-acetylhexosaminidase at each time period is shown by the solid line ( $\longrightarrow$ ) and the substrate blank, by the dotted line $(\cdots)$. The incubation times were [2] $440,[3] 385$, [4] $330,[5] 275$, [6] $220,[7] 165$, and [8] 110 s, respectively.

reproducibility of duplicate samples by the automated procedure was 2 to $4 \%$ as compared to 5 to $7 \%$ obtained manually.

The AutoAnalyzer, modified as described above, was also used for enzyme rate studies and yielded results similar to those shown in Fig. 4. Initial reaction rates were determined by expressing the results as micromoles of $p$-nitrophenol released per time of incubation. Using this methodology, the experimental $K_{m}$ value determined for bovine testicular $\beta$-hexosaminidase with pNP-GlcNAc as substrate was $1.45 \times 10^{-3} \mathrm{M}$; determined manually the $K_{m}$ was $1.5 \times 10^{-3} \mathrm{M}$.

The utility of the above described simple automated procedure has been ascertained in analyzing mammalian and microbial tissue extracts for the presence of several glycosidases $(\beta$-hexosaminidase, $\alpha$-mannosidase, and 
$\beta$-mannosidase) and in assaying for contaminating glycosidases in highly purified glycosidase preparations. As described the methodology is readily applied to the determination of such kinetic parameters as $\mathrm{pH}$ optima, substrate saturation, and the effects of inhibitors and cofactors and offers the advantage of low substrate and enzyme consumption.

\section{REFERENCES}

1. Delvin. E., Pottier, A., Scriver, C. R., and Gold, R. J. M. (1974) Clin. Chim. Acta $53,135$.

2. Lowden. J. A., Skomorowski, M. A., Henderson. F., and Kabach, M. (1973) Clin. Chem. 19,1345 .

3. Tucker, S. M., Boyd, P. J. R., Thompson, A. E., and Price, R. G. (1975) Clin. Chim. Acta 62, 333.

4. Rosenthal. A. L., and Saifer, A. (1973) Anal. Biochem. 55, 85.

5. Bradley, D. W., and Tappel. A. L. (1970) Anal. Biochem. 33, 400.

6. Tappel. A. L., and Beck, C. (1965) in Automated Analytical Chemistry, Technicon Symposium (Skeggs, L. T. J., ed.), p. 559. Mediad, New York.

7. Tappel, A. L. (1964) Abstracts Technicon International Symposium, New York, Paper No. 32, September.

8. Beck, C., and Tappel. A. L. (1967) Anal. Biochem. 21, 208.

9. Sarber, R., Distler, J. J., and Jourdian, G. W. (1978) in Methods in Enzymology Vol. 50, p. 520. Academic Press, New York.

10. Mcllvaine, T. C. (1972) J. Biol. Chem. 49, 173.

11. Morganstern, S., Chaparian, L., Vlastelica. D., and Keiderer, A. (1970) Advances in Automated Analysis. Technicon International Congress, Vol. I, p. 85. Futura, New York.
R. SARBER ${ }^{3}$
A. LANGNAS
G. W. JOURDIAN

The Rackham Arthritis Research Unit and the Department of Biological Chemistry University of Michigan Medical School Ann Arbor, Michigan 48109

Received March 27. 1978

\footnotetext{
${ }^{3}$ Supported by National Institutes of Health predoctoral Training Grant GM 00187.
} 